\title{
The many facets of alcohol policy
}

\section{Editorial}

The articles in this section are revised from papers presented at a thematic meeting on alcohol policy research of the Kettil Bruun Society for Social and Epidemiological Research on Alcohol, held in Melbourne in September, 2014. The international meeting was titled "Alcohol Policy Research: Putting Together a Global Evidence Base,” with attendees from 15 countries across five continents, including researchers from Australia, Europe, North America, Africa, and Asia. Papers revised from presentations at the conference are also published as special issues or sections in three other journals: Alcohol and Alcoholism (in Volume 50, No. 6), Drug and Alcohol Review (in Volume 35, No. 1), and Contemporary Drug Problems (in Volume 42, No. 2).

As is illustrated in the papers published here, research relevant to alcohol policy covers a wide variety of areas. In the first place, in modern governments divided into departments or ministries on the basis of functions, alcohol issues reach across a diversity of departments. A report for the British government - eventually published in Sweden beyond the reach of the UK Official Secrets Act (Bruun, 1982)—once counted how many British government departments had jurisdiction over one or another aspect of alcohol policy. The count at that time (shortly before Thatcher took office as Prime Minister) was 17. The count partly reflects the Balkanization of responsibilities in modern governments, but it also says something about the inherent multidimensionality of alcohol issues and problems.

In the second place, responsibilities for dealing with alcohol issues are typically divided between different levels of government. In Australia, for instance, control of alcohol advertising and tax levels is primarily a responsibility of the national government; the licensing system for alcohol sales and the response systems such as policing and alcohol treatment are state responsibilities; local government's responsibility for "community amenity" (e.g., safe public spaces and livable neighborhoods), as this is affected by alcohol intoxication, is exercised through such mechanisms as planning controls and conditions.

In the third place, research relevant to policy must reach well beyond the obvious area of policy impact researchthat is, studies which examine the effect of laws or regulations, most cogently by studying changes in the laws or regulations. Also highly relevant are studies of the formation of policies, including studies of public opinion and discourse related to the policies, studies of whether and how the laws and regulations are implemented, and studies of social group norms, practices, and problems actually or potentially affected by the laws or regulations, and how these practices are or might be affected by or may undercut the effects of the laws and regulations.

The papers in this thematic section give a fair sampling of the diversity of policy frames in which alcohol issues come up. The paper by Giesbrecht et al. (2016) works in a central ground for policy research, policy impact studies, summarizing and discussing the findings of a decade's worth of studies on the effects of two types of policy levers which governments have classically used at least in part to try to limit problems from drinking: alcohol taxes and limits on times and places of sale. The primary focus of these studies has often been simply on whether there is an effect at the level of the whole population, but Giesbrecht et al. (2016) pull together what has been found at the level of subpopulations: the evidence on differential effects of the various measures on different parts of the population. The paper finds substantial evidence that an increase in alcohol prices is associated with a reduction in alcohol consumption and several types of harms among youth, heavy drinkers, and low socio-economic status groups, and that an increase in alcohol availability is associated with an increase in alcohol consumption and alcohol-related harms. The paper also notes that the effects of control measures are often stronger on rates of alcohol-related harms than on levels of alcohol consumption. Behind this, we suggest, are two factors: that the difference is likely to reflect in part greater effects of price and availability controls on marginalized populations more at risk of harm, and in part that risk of many harms rises exponentially with higher consumption levels. A tax increase may have less proportional effect (a lower price elasticity) among heavy drinkers than light drinkers but may still have a strong effect on alcohol-related harm, since two drinks fewer per day or on an occasion affects risks for heavy drinkers more than for light drinkers.

Three of the papers, by Wittman (2016a, b) and Swensen (2016), address local controls at the city level—Wittman's two papers more broadly, in terms of availability controls, and Swensen's more narrowly, in terms of regulations of advertising in public space controlled by the local government. The three papers are more about policy 
formation and development than about impact, and they illustrate how gradual and incremental policy change can be. While each centers on the local level, all three papers find it necessary to bring in the other levels of government that are involved: the state of California in Wittman's papers, Western Australia in Swensen's. Wittman's first paper gives a summary account of the options for California local governments to control alcohol availability, as they have developed since 1980 through a series of initiatives by particular cities that were then tested and approved in courts. The cumulative result has been that California local governments have taken for themselves increased power to control the local alcohol market in the interests of diminishing nuisance and increasing amenity in their communities. Though Wittman's story is specifically about California, it contains ideas and lessons for other jurisdictions where local governments find themselves with little control over alcohol sales that are adversely affecting the community. Wittman's second paper takes a more historical perspective on the development of local government control in California between 1980 and 2015, describing the players and processes involved, and the trajectory of change, which was cumulative until about 2005 but has since stagnated. Wittman's summary of the current situation is that California is "halfway there," and he suggests elements that are needed for further progress in preventive local control of retail alcohol outlets in California cities.

An intrinsic element in Wittman's analysis is the dance between not only departments of government but also levels of government that is often required in alcohol policy formation and implementation. Swensen's study of control of alcohol advertising in public spaces in Western Australia deals with a topical area-alcohol advertising - that is often considered in Australia to be the responsibility only of the national level of government. His paper argues that this is not so, since local governments in Australia own and control a great deal of public space and have the ability to set conditions on how that space is to be used, including for advertising. His case study of Subiaco and its sports Oval illustrates that a third level of government, the state, can also be a player in this topical area. Swensen shows that local governments in Western Australia do have more powers than they often recognize over such dimensions as the ubiquity of alcohol advertisements, which has been linked with the growth of alcohol use and alcohol-related harms. But, as in the history Wittman describes, the situation is unstable and subject to influence by powerful private interests.

The paper by Riazi and MacLean (2016) relates to policy in less direct terms, studying the injunctive norms on collective drinking practices among young Australians. The authors draw their material from observations of drinking by groups of young people in public spaces, in which they find that drinking is both collective and a part of sociability. As is common in English-speaking societies, there are strong cultural norms in Australia about "shouting"- treating or buying rounds of drinks in social get-togethers. Riazi and MacLean report that their informants' almost unanimous experience was that round- buying increased their alcohol consumption above what it would otherwise have been. The paper discusses the implications of its findings for alcohol policy. It is noted that policies that restrict buying multiple drinks at a time have a long history - in fact, round-buying was forbidden during the First World War in parts of the UK (Grundy, 2010)_but that there is little modern evidence concerning the effects of restrictive policies in this area. With regard to this, it would be interesting to compare amounts and rates of drinking on social occasions in comparable social groups in different parts of Europe, since drinking groups in Nordic countries, for instance, do not practice buying rounds as is customary in Anglophone countries.

The paper by Reitan (2016) is concerned with policy and its implementation concerning drinking as a risk factor for harm in a specific area of the welfare system: social workers' investigations and conclusions concerning drinking by pregnant women in their caseload. Her research materials are the reports and recommendations made by Swedish social workers concerning whether the state should intervene in the case. In Swedish law, the potential effects of alcohol on the woman are a relevant consideration, but not the potential effects on the fetus. But Reitan finds that many of the reports do in fact take into account effects on the fetus, and some essentially ignore the law by citing the effects as a reason for state intervention. In such reports, the social workers clearly have an implicit moral code about the hierarchy of values concerning action when a pregnant woman is drinking that differs from the official hierarchy of values in the Swedish legislation. Reitan's paper reminds us how much drinking behavior is surrounded by and interpreted in terms of moral values, which influence not only policies but also how they are actually applied.

Overall, the papers in this special issue illustrate the wide variety of research topics and approaches that are relevant to alcohol policy. We hope that they will serve to increase discussion of alcohol policies in their varied facets and contribute to policy formation and implementation so as to limit health and social harms in and across different government functions and levels.

\section{References}

Bruun, K. (Ed.). (1982). Alcohol policies in United Kingdom. Stockholm, Sweden: Stockholm University, Sociology Department, Studier i svensk alkoholpolitik (Studies in Swedish alcohol policy).

Giesbrecht, N., Wettlaufer, A., Cukier, S., Geddie, G., Gonçalves, A.-H., \& Reisdorfer, E. (2016). Do alcohol pricing and availability have differential effects on subpopulations? A commentary. International Journal of Alcohol and Drug Research, 5(3), 89-99.

Grundy, J. (2010). 'Lloyd George's beer' or when it was illegal to buy your round. London, England: Western Front Association. Retrieved from http://www.westernfrontassociation.com/component/c ontent/article.html\#sthash.mqSAWOpA.dpbs 
Reitan, T. (2016). Arguing the case: Committing pregnant substance abusers to compulsory care. International Journal of Alcohol and Drug Research, 5(3), 131-139.

Riazi, S., \& MacLean, S. (2016). Young adults' accounts of buying rounds of alcoholic drinks for friends: Implications for harm reduction. International Journal of Alcohol and Drug Research, 5(3), 125-129.

Swensen, G. (2016). Public space and alcohol advertising: Exploratory study of the role of local government. International Journal of Alcohol and Drug Research, 5(3), 117-123.

Wittman, F. (2016a). Halfway there - The evolution of local alcohol control in California: Part I. The system as it has developed. International Journal of Alcohol and Drug Research, 5(3), 101-107.

Wittman, F. (2016b). Halfway there - The evolution of local alcohol control in California: Part II. Stages and factors in development, 1980-2015. International Journal of Alcohol and Drug Research, 5(3), 109-116.

Heng Jiang, Ph.D.

Centre for Alcohol Policy Research

La Trobe University

Melbourne, Australia

Robin Room, Ph.D.

Centre for Alcohol Policy Research

La Trobe University

Melbourne, Australia

and

Centre for Social Research on Alcohol and Drugs

Stockholm University

Sweden 